\title{
Investor's Anticipation and Future Market Movement: Evidence of Self- Fulfilling Prophecy Effect from Chinese Stock Market
}

\author{
Yun Wan \\ University of Houston - Victoria \\ wany@uhv.edu
}

\author{
Xiaoguang Yang \\ AMSS, Chinese Academy of Science \\ xgyang@iss.ac.cn
}

\begin{abstract}
We analyzed data collected from retail investors in Chinese stock market from a fin-tech mobile platform to find evidence of self-fulfilling prophecy effect. We found statistically significant correlation between the predicted and actual Shanghai Stock Exchange Composite Index (SSECI) as well as nonrandom deviation patterns. We also analyzed participating investor behaviors and discussed the implications and future research.
\end{abstract}

\section{Introduction}

Can we predict stock market movement? Among the dominant normative financial market theory, the efficient market hypothesis (EMH) states that historical stock prices fully reflect all available information. So it is impossible to "beat the market" consistently on a risk-adjusted basis [5]. The rationale of EMH is self-evident. However, still, there were many methods being used by investors to capture stock investment opportunity or forecast future stock trend. Among these methods, a majority are the so called technical analysis, that is using sophisticated statistical analysis techniques to analyze historical stock market data[16], such as Japanese candlesticks [15] and other charting methods [18].

In recent years, a study in behavioral finance found human behavior could significantly influence financial market movement. For example, the cognitive bias in human behavior, such as hyperbolic discounting[11] combined with financial market complexity [1], and herding habit by investors [4] are central to the global financial crisis of $2008[7,13]$.

Having or changing expectation on future market movement is one of the most common investor behavior. If market participants' expectation influences a stock market movement, then selffulfilling prophecy effect exists. Several recent studies have confirmed the existence of such influence in social and economic activities [17, 19, 20]. For a stock market mainly driven by investor expectation instead of economic fundamental, we expect the self-fulfilling prophecy effect would be more significant. Thus, an interesting research question is: Does the investors' expectation affect the stock market fluctuation?

In this study, we explored this research question by using data collected from retail investors of the highly speculative Chinese stock market and found evidence of such correlation. The remaining of this paper consists of three sections, in the literature review section, we introduced crowdsourcing and information market, explained that Chinese stock market is a highly speculative market that could be influenced by investors' expectations. Next, we explained data collection details and the preprocessing measures. In the last section, we presented data analysis outcome as well as its implication for information market research and financial market practitioners.

\section{Literature review}

\subsection{The wisdom of the crowd}

In 1906, British statistician Francis Galton found that though ordinary villagers had no knowledge of how much meat a cattle could produce, their aggregated guess could reach almost the exact right weight. Thus, he concluded that even when most participants have little professional knowledge, when there is big enough crowd, their aggregated amateur wisdom is still close to actual result [6]. This is one of the earliest examples of so-called the wisdom of the crowd [21].

To fully unleash the power of the crowd and get an accurate outcome, we need a large enough participation and independent estimation from each of them. These are two conditions crucial for the wisdom of the crowd. Such requirements could be costly to setup. However, the Internet and World 
Wide Web provide an easy and costless method to reach and assemble a large but diversified online crowd. It also allows us to collect and aggregate their independent prediction in real time. As a result, information economists have experimented on Webbased information prediction market, which aggregating disperse information contributed by individuals into efficient forecasts of uncertain future events[9].

They found that such market outperforms most moderately sophisticated benchmarks. Information markets have been applied in almost all socialeconomic aspects of our daily life. The rule of thumb for organizing such market is to allow those individual participants who have insights on an issue to be incentivized to reveal their real insights independently[22].

One successful example of such market is Iowa Electronic Market or IEM, designed and created by faculty members at the University of Iowa in 1998[8]. This information market used a naturally occurring future market trading mechanism to encourage participants betting on their insights in US political environment. It successfully predicted the outcome of US presidential election in the last 18 years[2].

Another classic example is the Hollywood Stock Exchange or HSX. HSX is a web-based, multiplayer game in which players use the pseudo money to buy and sell "shares" of actors, directors, upcoming films, and film-related options [12]. HSX could be used to predict the box office performance as well as other movie related competitions. In 2007, HSX Players correctly predicted 32 of the 39 majorcategory Oscar nominees and seven out of eight topcategory winners.

The successful experience of using crowdsourcing method in information market to gain insights and predict future events indicated there is a cost-effective way to polling/crowdsourcing retail investors' expectation or prediction on future stock market movements, i.e. the movement of Shanghai Stock Exchange Composite Index.

\subsection{Speculative market}

Chinese stock market is different from the western stock market because of its speculative nature [3]. There are three unique characteristics of Chinese stock market that led to its speculative nature:

Firstly, Chinese stock market mainly consists of retail investors. There are more than 200 million trading accounts in China, which is about the size of the whole adult population in the United States ( http://finance.sina.com.cn/stock/hyyj/20150429/0439 22068458.shtml) With so many retail investors, Chinese stock market price movement is characterized by individual investors' speculation and herding behavior [25]. In contrast, U.S. stock market mainly consists of institutional investors and their investment behavior is more rationalized and guided by rigorous risk control protocols.

Secondly, though there is a large number of open trading accounts, the long term owner of Chinese stock is less than $7 \%$ of the population [5]. Only recently did the Chinese government begin to consider allowing retirement pension fund into the stock market, which is in sharp contrast to the U.S., where various pension funds held the significant stake in the stock market. Thus, Chinese retail investors trading activity is mostly in the form of short-term speculation, i.e., day traders. And such thinking is mainly motivated by short-term stock price change and influenced by herding behavior rather than company fundamentals.

Thirdly, Chinese retail investors believe the central government would serve as the last resort of rescue and ultimate market booster[23]. Specifically, they expect the central government to save the market when there is a market crisis and boost the market when there are major political events like government or party re-election that needs a harmonious society support. Indeed, the central government has served such a role since the creation of a stock exchange in China [24]. Such involvement reinforced expectation of retail investors and increased speculation behavior.

All these factors made Chinese stock market extremely susceptible to speculation and selffulfilling prophecy effect.

\subsection{The self-fulfilling prophecy effects}

There is a critical difference between a stock index or the results of a presidential election and the weight of a cattle: a stock index or an election outcome may be adaptive to on-going prediction. Such adaptations are susceptible to self-fulfilling prophecy effect, of which a prediction that directly or indirectly causes itself to become a reality, by the very terms of the prophecy itself, due to positive feedback between the belief and the behavior [14].

Self-fulfilling prophecy effect has been observed in the political domain. For example, once people learn about prevailing public opinion via ubiquitous polls or political prediction market (like Iowa electronic market, which has contract price and aggregated polling summaries), such polls or opinions may influence their subsequent voting 
decision. Consequently, polling results can become self-fulfilling prophecies whereby majorities, whether in support of candidates or policies, grow in a cascading manner due to positive feedback [20]. We could also find such an effect in the domain of economic decision-making. An experiment conducted by three Netherland researchers found that speculative forecasts of economic change can impact individuals' financial decision behavior, before any realized changes [17].

These findings suggest that forecasted positive or negative change of social or economic activities can influence people's mental model, reduce or stimulate risk taking, and lead to intended outcome.

In summary, since Chinese stock market is a highly speculative market, retail investors' prediction of the market movement could become a selffulfilling mechanism, trigger a positive feedback loop, even leading to stock market bubble or crisis when other conditions meet [25]. With this observation and assumption, it is possible to find evidence of such effect by studying the correlation between predictions made by retail investors and actual market movement. We can also expect the larger the polling base, the higher the correlation we would identify.

Since the influence of speculative forces may not be consistent across a single stock, we used macro level market movement variables, such as Shanghai Stock Exchange Composite Index (SSECI), as polling target. The comprehensive coverage of SSECI could manifest overall market speculation direction because it has been observed and used by all retail investors. Thus, in our study, we used the crowd-sourcing prediction of SSECI to find evidence of self-fulfilling prophecy effect.

\section{Data collection and cleaning}

Based on prior discussion and our research question, we propose that there is a statistically significant correlation between retail investor prediction and actual Chinese stock market movement index like SSECI.

To verify our hypothesis, we collaborated with a Beijing-based Fintech company (referred as Company A). This company is specializing in innovative stock market investment tools. It operated and maintained a mobile app as well as WeChat platform for its products and services. The collaboration allows us to tap into this company's user base, which mostly consists of Chinese stock market investors.
The platform allows participants to predict the movement of SSECI index up to next six months through its WeChat Public Account. WeChat Public Account is an HTML5 mobile webpage accessible via WeChat APP on a mobile phone. Because most Chinese have a WeChat account on their mobile phone, companies could collect data via interactive features of this account just like using an APP. This avoids the hassle of downloading additional APP so it is preferred by many start-up companies in China.

Investors could enter their predicted index as well as the expected realization date via their mobile phone. After sending in their prediction, as a reward, they would be able to view the most-recent aggregated forecast for the next seven days, which was continuously calculated and generated by the backend server. Figure 1 is the WeChat interface we used to collect the data as well as the aggregated prediction chart to participants.

The data collection process lasted from January 2016 through July 2016. After the data collection, we obtained a data set with a total of 214451 data points contributed by 24938 different retail investors. The date of contribution ranges from January 5, 2016, to July 20, 2016.

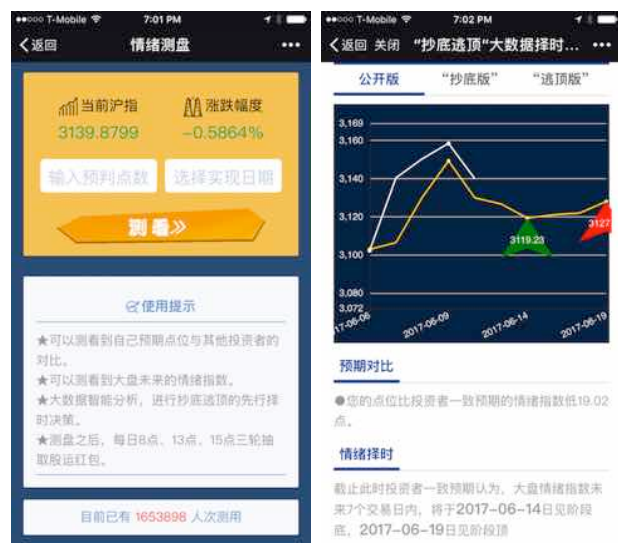

Figure 1(right): WeChat data collection interface (left) and results are shown to participants (right)

We processed the data set with standard data cleaning procedures. It included the elimination of prediction on a single stock and out of range data due to random or error input. Because the stock index rarely rises or drops more than $3 \%$ within a day we regard any prediction that exceeds such limit as abnormal and eliminated them. Company A also provides forecasting service on a single stock. The data set we received contained such prediction and they were also removed. 
Finally, we removed data with invalid dates, i.e., those before 2016 due to database or input error, those prediction dates before or on the dates when the prediction being made, and those prediction dates fall on non-trading dates. Table 1 is a summary of data cleaning outcome.

\section{Table 1 Invalid data distribution}

\begin{tabular}{|c|c|}
\hline Invalid Data Type & \\
\hline Predictions on single stock & 40037 \\
\hline Single day fluctuation exceeds $3 \%$ & 65781 \\
\hline Predictions before trading day & 227 \\
\hline \multirow[t]{2}{*}{ Out of date range prediction } & 7928 \\
\hline & 113973 \\
\hline
\end{tabular}
removed each category in order

After the data cleaning, we retained a total of 100,446 effective data observations. We used a scatter plot to illustrate its distribution (Figure 2). Different color in the figure indicated a varying degree of data density on dates.

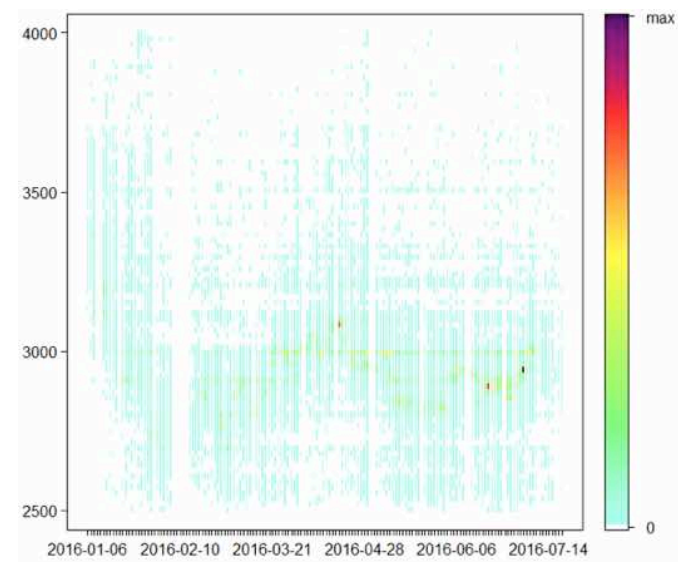

Figure 2 Scatter plot of cleaned dataset, color indicates data density

\section{Data analysis}

\subsection{Predicted vs. Actual Index}

We first compared average daily predicted index with actual daily index and found the former significantly correlated with the latter (Pearson Correlation: 0.8698 , p-value <2.2e-16), which validated our self-fulfilling prophecy effect hypothesis (Figure 3).
We also found the average deviation of predicted index to actual index is 31.706 and not randomly distributed $(p$-value $=9.671 \mathrm{e}-07)$. The correlation between the deviation and actual index is -0.3486918 . This non-random deviation consists of a pattern: the magnitude of actual index fluctuation always exceeds that of the corresponding predicted index. For example, when an actual index was in a downturn for a period and change its direction to upward, the magnitude of risen-up would exceed the predicted risen-up, vice versa.

This pattern further confirmed our hypothesis. The stronger the speculation, the more intense of positive feedback loop under self-fulfilling prophecy effect. When most investors believe there is a change in stock market direction, we could expect the aggregated result would exceed the early expectation with increasing number of investors taking action to reinforce the belief.

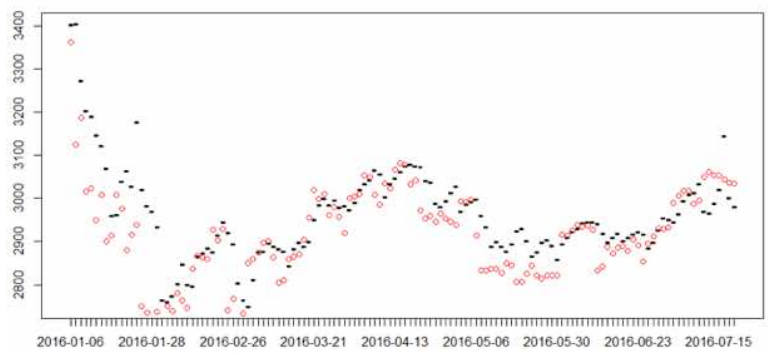

Figure 3 Predicted index (in black) vs. actual index (in red)

Linear and nonlinear Granger causality tests are often used to examine the dynamic relationship between the stock index and return changes [10]. To further analyze the correlation between predicted and actual SSECI index, we used Granger causality test to examine the relation between average predicted index, median predicted index, and actual index (Table 2). We found the significant mutual causal relationship between the average predicted index and actual index. Though actual index is influenced by multiple factors, this indicated self-fulling prophecy induced retail investor prediction is at least one contributing factor to the fluctuation of actual index.

Table 2 Granger causality test result

\begin{tabular}{lllll}
\hline \multirow{2}{*}{ Orders } & \multicolumn{2}{c}{ First-order lag } & \multicolumn{2}{c}{ Second-order lag } \\
\cline { 2 - 5 } & A、C & B、C & A、C & B、C \\
\hline p-value (1) & $0.01348^{*}$ & 0.3725 & $0.0007843^{*}$ & $0.02182^{*}$ \\
p-value (2) & $5.996 \mathrm{e}-09^{*}$ & $2.2 \mathrm{e}-16^{*}$ & $9.853 \mathrm{e}-09^{*}$ & $2.2 \mathrm{e}-16^{*}$ \\
Conclusion & Mutual & C cause B & Mutual & Mutual
\end{tabular}


Note: A: average predicted index, B: median predicted index, $\mathrm{C}$ : actual index, (1) indicate left to right causal relation (2) indicate right to left causal relation and " * " indicate statistically significant

\subsection{User behavior analysis}

Understanding investor participating behavior would give us more insights into the self-fulfilling prophecy effect in Chinese stock market. Figure 4 is the frequency of individual investor participation during the data collection period.

We found $76 \%$ of participating investors contribute 5 or fewer times, $86 \%$ contribute 10 or less times, and $90 \%$ contribute 15 or fewer times. This indicated most prediction data we collected is like randomly selected user participation. They are mostly independent of each other. This feature has both its pros and cons: More active participation by a single investor could help us build the track record of the investor but only on the condition that one has a good estimation of the index.

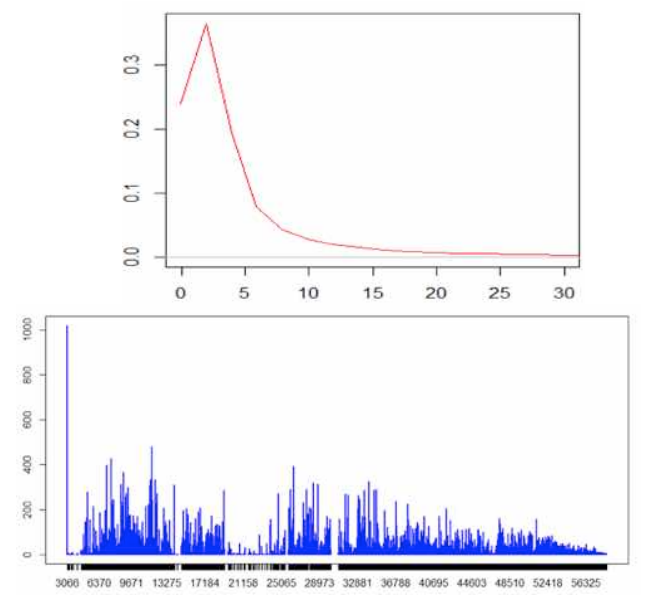

Figure 4 User participation frequency (top) and distribution of user ID (bottom)

Chinese stock market opens at 9:30 am and closes at $15 \mathrm{pm}$. It is not surprising that most participants contribute their index prediction between 7 am to 3 pm. Figure 6 shows that the intraday predicting time points of the investors. We can see that the investors prefer to make their prediction within 2 hours of morning market opening, stop making predictions during morning trading hour, resume prediction and reach climax at $12 \mathrm{pm}$, during the lunchtime, then continue making predictions until the close time at 3 pm.

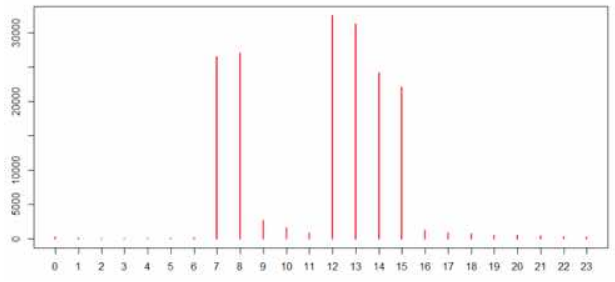

Figure 5 Distribution of prediction time

How many days ahead investors tend to predict? Based on our dataset, participants on average made their predictions ahead of 16.81 days, more than half a month. We found most predictions forecast fall within the range of 13 to 27 days in advance though some could be 3 to 6 months.

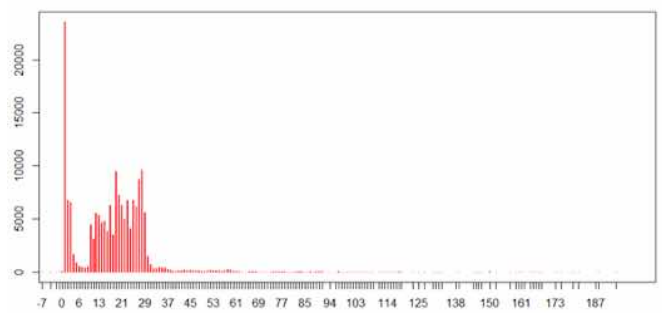

Figure 6 Distribution of lead time

Not all participants have equal predictive power. We found the distribution of participants regarding predictive power in our experiment follows 20-80 laws. That is the top $20 \%$ of participants predicted index have about $99.53 \%$ correlation with actual index. In contrast, the bottom $80 \%$ has a correlation of only about $87.47 \%$.

Table 3: Distribution of prediction accuracy

\begin{tabular}{rllll}
\hline Groups & Participants & Weight & Avg. dev. & Correlation \\
\hline Dev. $<15$ & 2965 & $21.70 \%$ & 7.405016 & 0.9953 \\
Dev. $>15$ & 10694 & $78.30 \%$ & 36.42826 & 0.8747 \\
Total & 13659 & $100 \%$ & 31.71935 & 0.8697 \\
\hline
\end{tabular}

\section{Implications}

This very preliminary study shed new light on using self-fulfilling prophecy effect to forecast and monitor the stock market trend in a speculative stock market scenario. Recent progress in behavior finance already found the importance of understanding investor behavior in identifying market dynamics. This study specifically indicated self-fulfilling prophecy effect could be utilized in a highly speculative market, which could help capture important market turning signal. 
Industry practitioners could consider creating a crowdsourcing stock index future market, like Iowa electronic market or HSX. Such market could encourage investors to put down a small amount of money as their bet on their prediction. As an incentive, investors would receive the monetary reward if their prediction are within the range of accuracy. Such information market would generate a future stock market movement index, complementary to index like SSECI. Such future market allows us to eliminate all non-committal data contributors and dramatically increase data quality. The S\&P Volatility Index in the United States is a good example in such direction.

\section{Conclusion}

In this study, we analyzed a data set about predictions on the future movement of Shanghai Stock Exchange Composite Index by Chinese retail investors via a mobile platform maintained by a Chinese financial service company. We tested and validated the self-fulfilling prophecy effect by identifying the correlation between retail investor predicted index and actual SSECI index movement. Our study demonstrated the possibility of using retail investor crowdsourcing method to generate a more sophisticated prediction market. We also analyzed investors behavior. Such behavior would help us better understand their decision-making process.

\section{Reference}

[1] Arthur, W.B. Complexity in economic and financial markets: Behind the physical institutions and technologies of the marketplace lie the beliefs and expectations of real human beings. Complexity 1, 1 (1995), 20-25.

[2] Berg, J., Forsythe, R., and Rietz, T. What makes markets predict well? Evidence from the Iowa Electronic Markets. In Understanding Strategic Interaction. Springer, 1997, 444-463.

[3] Cendrowski, S. Here's What You May Not Know about the Chinese Stock Market. 2015.

[4] Devenow, A. and Welch, I. Rational herding in financial economics. European Economic Review 40, 3 (1996), 603-615.

[5] Fama, E.F. Efficient Capital Markets: A Review Of Theory And Empirical Work. The Journal of Finance 25, 2 (1970), 383-417.

[6] Galton, F. Vox populi (The wisdom of crowds). Nature 75, 1949 (1907), 450-451.

[7] Gärling, T., Kirchler, E., Lewis, A., and Van Raaij, F. Psychology, financial decision making, and financial crises. Psychological Science in the Public Interest 10, 1 (2009),
$1-47$.

[8] Gomme, P. Iowa electronic markets. Federal Reserve Bank of Cleveland, (2003).

[9] Grover, V. and Teng, J.T.C. E-commerce and the information market. Communications of the ACM 44, 4 (2001), 79-86.

[10] Hiemstra, C. and Jones, J.D. Testing for linear and nonlinear Granger causality in the stock price- volume relation. The Journal of Finance 49, 5 (1994), 1639-1664.

[11] Kahneman, D. A psychological perspective on economics. The American economic review 93, 2 (2003), $162-168$

[12] Levmore, S. Simply Efficient Markets and the Role of Regulation: Lessons from the Iowa Electronic Markets and the Hollywood Stock Exchange. J. Corp. L. 28, (2002), 589.

[13] McDonald, I.M. The global financial crisis and behavioural economics. Economic Papers: A journal of applied economics and policy 28, 3 (2009), 249-254.

[14] Merton, R.K. The self-fulfilling prophecy. The Antioch Review 8, 2 (1948), 193-210.

[15] Nison, S. Japanese candlestick charting techniques: a contemporary guide to the ancient investment techniques of the Far East. Penguin, 2001.

[16] O'Neil, W.J. and Ryan, C. How to make money in stocks. McGraw-Hill New York, 1988.

[17] Petalas, D.P., Van Schie, H., and Vettehen, P.H. Forecasted economic change and the selffulfilling prophecy in economic decisionmaking. PLoS ONE 12, 3 (2017), 118.

[18] Pring, M.J. Technical analysis explained: The successful investor's guide to spotting investment trends and turning points. McGraw-Hill Professional, 2002.

[19] Riegler, M., Gaddam, V.R., Larson, M., Eg, R., Halvorsen, P., and Griwodz, C. Crowdsourcing as selffulfilling prophecy: Influence of discarding workers in subjective assessment tasks. Proceedings - 14th International Workshop on Content-Based Multimedia Indexing (CBMI), IEEE (2016), 1-6.

[20] Rothschild, D. and Malhotra, N. Are public opinion polls self-fulfilling prophecies? Research \& Politics 1, 2 (2014), 205316801454766.

[21] Surowiecki, J. The wisdom of crowds. Anchor, 2005.

[22] Wolfers, J. and Zitzewitz, E. Prediction markets. The Journal of Economic Perspectives 18, 2 (2004), 107-126.

[23] 乔桂明. 中国股票市场 “政策市” 之博亦分析. 经济科 学, 2 (2004), 65-73.

[24] 许均华and 李启亚宏观政策对我国股市影响的实 证研究 经济研究9, (2001), 61.

[25] 马洪潮 中国股市投机的实证研究 金融研究 3 (2001), 1-9. 